\title{
Retrospective analysis of microbiological profile of patients with infective keratitis: North Indian perspective
}

\author{
Shazia Qayum ${ }^{1, *}$, Vineet Gupta $^{2}$, Jyoti Chauhan ${ }^{3}$ \\ ${ }^{\mathbf{1}}$ Senior Resident, ${ }^{\mathbf{2}}$ Assistant Professor, ${ }^{\mathbf{3}}$ Tutor, Dept. of Ophthalmology, ${ }^{\mathbf{1}, 2}$ Maharishi Markandeshwar Institute of Medical \\ Sciences and Research, Ambala, Haryana, ${ }^{3}$ Government Doon Medical College, Dehradun, Uttarakhand, India
}

*Corresponding Author: Shazia Qayum

Email: dshazbeig@gmail.com

\begin{abstract}
Introduction: Infectious keratitis is among the leading causes of preventable blindness in developing countries. The epidemiological profile of infectious keratitis vary significantly from country to country and even area to area within the same country.

Aim: This study was conducted to know the epidemiological pattern, predisposing risk factors involved and microbiological profile of the patients with corneal ulcer.

Materials and Methods: A retrospective analysis of all the patients presenting to MMIMSR eye opd with corneal ulcer between Jan 2016 to June 2018 was done. The demographic data as well as epidemiological profile including history of trauma, duration of symptoms, predisposing risk factors, time taken to present to hospital was collected. The diagnosis was made based on clinical findings on Slit lamp examination as corneal epithelial defect with stromal infiltrate and microbiological investigations.

Results: There were a total of 234 patients documented to have corneal ulcer. The mean age of presentation was $46 \pm 18$ years. Only $20(8.6 \%)$ presents within a week of symptoms and 122 patients $(52.1 \%)$ presented within 2 to 4 week of symptoms. A history of ocular trauma was present in about 150 patients (64\%) out of which trauma with vegetative matter in $88(58.67 \%)$ patients and trauma with non vegetative matter in 51 (34\%) patients. Corneal scrapping was positive in 185 patients (79.04\%) with $\mathrm{KOH}$ mount being positive in 152 patients (64.95\%). Gram stain was positive for bacteria in 21 patients $(8.97 \%)$ and 12 $(5.12 \%)$ patients reported both bacteria and fungus. In 47 patients $(20.08 \%)$, no organism was reported. Among the gram positive isolates, Staphylococcus epidermidis was the most frequent species. The most common fungal isolate reported was fusarium in 49 patients (26.48\%) followed by Aspergillus in 19 patients (10.27\%).

Conclusion: Infective keratitis is a common cause of ocular morbidity with fungal corneal ulcer being the most frequent ulcer. Fusarium species in fungal corneal ulcer and staphylococcal epidermidis in bacterial corneal ulcer were the common isolates. A lack of knowledge about the magnitude of the problem, financial limitations and topographical constrains were implicated in delayed presentation to a health center.
\end{abstract}

Keywords: Corneal ulcer, Corneal opacification, Infective keratitis, Ocular trauma, Preventable blindness.

\section{Introduction}

Infectious keratitis is among the leading causes of preventable blindness in developing countries. It has been labeled as a "silent epidemic" in underprivileged countries. ${ }^{1}$ Corneal opacification is a major cause of visual impairment after cataract in many parts of the world like Middle East, Asia and Africa. ${ }^{2-5}$ Various studies showed variations in the incidence of corneal ulceration with United States showing incidence rate of 11 per 100,000 in a year, ${ }^{6}$ India with incidence rate of 113 per 100,000 in a year ${ }^{3}$ and Nepal with 799 per 100,000 / year. $^{7}$ The epidemiological profile of infectious keratitis vary significantly from country to country and even area to area within the same country. The various studies have shown the prevalence of different types of infectious keratitis in various parts of the world. ${ }^{8}$ The diagnosis of keratitis relies on a thorough history, epidemiological pattern and its morphological features. ${ }^{7}$ So it is very important for every hospital to develop a strategic approach for the diagnosis, timely management and prevention of infectious keratitis. This study was conducted to know the epidemiological pattern, predisposing risk factors and microbiological profile of the patients with corneal ulcer.

\section{Materials and Methods}

A retrospective analysis of all the patients presenting to MMIMSR eye opd with corneal ulcer between January 2016 to June 2018 was done. Corneal ulcer was diagnosed as loss of corneal epithelium with underlying stromal infiltration with signs of inflammation with or without hypopyon. The demographic data as well as epidemiological profile including history of trauma, duration of symptoms, predisposing risk factors, time taken to present to hospital was collected. The diagnosis was made based on clinical findings on Slit lamp examination as corneal epithelial defect with stromal infiltrate and microbiological investigations. The referred patients of corneal ulcer who were on topical antibiotics with negative cultures were included if their clinical picture was suggestive of infectious corneal ulcer. Visual acuity (VA) of these patients was divided into four categories (as per WHO guidelines): those between $6 / 6$ to $6 / 18$ (acceptable), $6 / 24$ to $6 / 60$ (moderate visual impairment), <6/60to 3/60 (severe visual impairment) 
and $<3 / 60$ (blind). All patients underwent a detailed slit-lamp examination and the corneal staining was done by putting fluorescence strip in the lower conjunctival fornix and the cornea was then examined with cobalt blue filter. The epithelial defect size was measured and recorded in millimeters and diagram of each ulcer was made and presence of hypopyon if any was also noted. Associated ocular pathology like blepharitis, dry eyes, dacryocystitis, lagophthalmos, contact lens use, ocular leprosy, corneal anesthesia and use of topical steroids were also documented.

All the patients underwent detailed ocular examination of eyelids and cornea under slit lamp and scraping of the cornea was taken (under LA like proparacaine $0.5 \%$ ) using sterile Bard-Parker knife from the leading edge and base of the ulcer. The sample obtained was inoculated into blood and chocolate agar media, stained for Gram stain and $\mathrm{KOH}$ wet mount. Statistical analysis was done using Microsoft excel 2016 Ed.

\section{Results}

There were a total of 234 patients documented to have corneal ulcer during our study period out of which $140(59.8 \%)$ were males and $94(40.1 \%)$ were females. The mean age of presentation was $46 \pm 18$ years with fourth to sixth decade being the most common age group having about $79 \%$ of patients in this age group. Only $20(8.6 \%)$ presents within a week of symptoms. About 122 patients $(52.1 \%)$ presented within 2 to 4 week of symptoms (Table 1). The delayed presentation was due to financial limitation, unawareness about severity of the problem and topographical constrains to seek health care. Of all the patients presenting to our institute, about 176 patients (75\%) were already putting some medications in the form of topical antibiotics eye drops in $22(12.5 \%)$, antifungal eye drops in 12 patients $(6.8 \%)$, both antibiotics and antifungal in $35(19.8 \%)$ patients and steroids in $08(4.5 \%)$ patients. A history of ocular trauma was present in about 150 patients (64\%) with trauma with vegetative matter (like grass, hay, sugarcane and leaf) in 88 (58.67\%) patients and trauma with non-vegetative matter in $51(34 \%)$ patients (Table 3).

The visual acuity at presentation was $<6 / 60$ in 150 patients (64.1\%), 32 patients (13.6\%) had visual acuity between $6 / 6$ to 618 and $52(22.2 \%)$ had visual acuity between $6 / 18$ to $6 / 60$. Out of 234 patients, 86 patients (36.7\%) had hypopyon at presentation. Corneal scrapping was positive in 185 patients $(79.04 \%)$ with $\mathrm{KOH}$ mount being positive in 152 patients $(64.95 \%)$. Gram stain was positive for bacteria in 21 patients $(8.97 \%)$ and $12(5.12 \%)$ patients reported both bacteria and fungus. In 47 patients $(20.08 \%)$, no organism was reported. In 02 patients $(0.8 \%)$, corneal scraping was not done due to risk of perforation (Table 2). Among the gram positive isolates, Staphylococcus epidermidis was the most frequent species followed by staphylococcus aureus (Table 4) and among Gram negative organisms pseudomonas aeruginosa was the common species. The most common fungal isolate reported was fusarium in 49 patients $(26.48 \%)$ followed by Aspergillus in 19 patients (10.27\%). Mixed bacterial and fungal isolates was noticed in $12(6.48 \%)$ (Table 4)\}

Table 1

\begin{tabular}{|l|c|c|}
\hline Duration of illness & $\begin{array}{c}\text { No. of } \\
\text { patients }\end{array}$ & \%age \\
\hline$<1$ week & 20 & $8.6 \%$ \\
\hline 7 to 14 days & 66 & $28.2 \%$ \\
\hline 15 to 30 days & 122 & $52.1 \%$ \\
\hline$>1$ month & 26 & $11.1 \%$ \\
\hline Total & 234 & $100 \%$ \\
\hline
\end{tabular}

Table 2: Microbiological growth pattern in 234 corneal ulcer patients

\begin{tabular}{|l|c|c|}
\hline Pattern of growth & $\begin{array}{c}\text { No. of } \\
\text { cases (n) }\end{array}$ & \%age \\
\hline Bacteria & 21 & $8.97 \%$ \\
\hline Fungus & 152 & $64.95 \%$ \\
\hline Mixed & 12 & $5.12 \%$ \\
\hline No organism & 47 & $20.08 \%$ \\
\hline Not done & 02 & $0.83 \%$ \\
\hline Total & 234 & $100 \%$ \\
\hline
\end{tabular}

Table 3: Predisposing risk factors in 150 patients of total 234 patients

\begin{tabular}{|l|c|c|}
\hline Predisposing factor & $\begin{array}{c}\text { No. of } \\
\text { patients }\end{array}$ & \%age \\
\hline Trauma & & \\
Vegetative matter & 88 & $58.67 \%$ \\
Non vegetative matter & 51 & $34 \%$ \\
\hline Dacryocystitis & 08 & $5.3 \%$ \\
\hline Other Ocular disorder & 03 & $2 \%$ \\
\hline Total & 150 & $100 \%$ \\
\hline
\end{tabular}

Table 4: Bacterial and fungal isolates from corneal ulcer

\begin{tabular}{|l|c|c|}
\hline \multicolumn{1}{|c|}{ Organism } & Single species isolates & \%age \\
\hline Staphylococcus epidermidis & 11 & $5.94 \%$ \\
\hline Staphylococcus aureus & 04 & $2.16 \%$ \\
\hline Staphylococcus pneumonia & 03 & $1.62 \%$ \\
\hline Streptococcus viridans & 01 & $0.54 \%$ \\
\hline Pseudomonas aeroginosa & 02 & $1.08 \%$ \\
\hline Fusarium species & 49 & $26.48 \%$ \\
\hline
\end{tabular}




\begin{tabular}{|l|c|c|}
\hline Aspergillus species & 19 & $10.27 \%$ \\
\hline Candida & 08 & $4.32 \%$ \\
\hline Unidentified dematicious fungi & 48 & $25.94 \%$ \\
\hline Unidentified hyaline fungi & 28 & $15.13 \%$ \\
\hline Mixed Bacterial and fungal growth & 12 & $6.48 \%$ \\
\hline Total & 185 & $100 \%$ \\
\hline
\end{tabular}

\section{Discussion}

Corneal ulceration is one of the major causes of blindness in underprivileged countries. Corneal scarring is next to cataract in causing visual disability in the world. ${ }^{1,9-12}$ Since ours is a tertiary center catering to adjoining rural areas and most of the population is involved in harvesting and about 128 patients $(54.7 \%)$ of total 234 were farmers. The similar occupational profile was noticed in a study conducted in West Bengal and southern India ${ }^{9,13}$ in comparison to a study done in Ghana which reported only $16.1 \%$ of patients being farmers. ${ }^{14}$ About 122 patients $(52.1 \%)$ in our study presented in 2 to 4 weeks of symptoms and only 20 patients $(8.6 \%)$ presented within a week of symptoms in contrast to a study conducted in south India, $60 \%$ of the patients reported within a week time ${ }^{9}$ while the study conducted by Dhakhwa et al ${ }^{15}$ noticed $43.2 \%$ of the patients presented within 2 to 4 weeks. In our study, the microorganisms were isolated in about 185 patients (79.7\%) which is analogous to a study done by Upadhaya et al. ${ }^{16}$ The study done by Dhakhawa et $\mathrm{al}^{15}$ reported culture positivity in $72.5 \%$ of the patients. Of all the patients with corneal ulcers, 152 (64.9\%) showed positive culture which were fungal in origin. This figure is higher than the fungal isolation rate in the study by Srinivasan et al who reported $46.8 \%$ and Hagan et al reported $51.9 \%$ while the study by Sitoula RP et $\mathrm{al}^{17}$ reported $70 \%$ culture positivity for fungus. The study by Lavaju et $\mathrm{al}^{18}$ reported $20 \%$ culture positivity for fungus. Among the fungal positive cultures, $26.48 \%$ were fusarium species, $10.27 \%$ were Aspergillus species, unidentified dematicious fungi in $25.94 \%$ and unidentified hyaline fungi in $15.13 \%$. The similar results were reported by Srinivasan et al where fusarium was the commonest identified fungus. In a study by Dhikhawa et al, the frequency of fungal culture positivity was Fusarium species (30.73\%), Aspergillus species 18 (10.06\%), dematiceous fungi $(57 ; 31.84 \%)$ and unidentified Hyaline fungi (22 i.e.12.29\%). In a study by Upadhyaya et al, Basak et al (2005) William et al., Aspergillus species was the most common fungal isolate. ${ }^{18}$ Of total 21 bacterial isolates, staphylococcus epidermidis was present in $52.3 \%$ and was the commonest followed by Staphylococcus aureus while in the study by Dhikhawa et al out of 186 isolates, Gram positive bacteria were accounting 157 cases $(84.41 \%)$ of total isolates. Among Gram positive isolates, Staphylococcal epidermidis was the most frequently isolated species with 55 cases $(29.57 \%)$, followed by Streptococcus viridians 28 cases $(15.05 \%)$.
While Streptococcus pneumoniae was the most common isolate in the study by Upadhyaya et al ${ }^{16-18}$ Staphylococcus aureus was reported to be the most common isolate in Basak et al, ${ }^{13}$ while Pseudomonas spp. was common isolate in study by Hagan et al ${ }^{14-22}$ and William et al. ${ }^{18-22}$

\section{Conclusion}

Infective keratitis is a common cause of ocular morbidity with fungal corneal ulcer being the most frequent ulcer. Fusarium species in fungal corneal ulcer and staphylococcal epidermidis in bacterial corneal ulcer were the common isolates. A lack of knowledge about the magnitude of the problem, financial limitations and topographical constrains were implicated in delayed presentation to a health center. There is need to initiate awareness programs at district level so that timely management can be instituted at the earliest and burden of ocular morbidity can be limited.

\section{References}

1. Whitcher JP, Srinivasan M. Corneal ulceration in developing world - a silent epidemic. Br J Ophthalmol. 1997;81:622-623.

2. Upadhyaya MP, Karmacharya PC, Koirala S, Tuladhar NR, Bryan LE, Smolin G et al. Epidemiologic characteristics, predisposing factors, and aetiologic diagnosis of corneal ulceration in Nepal. Am J Ophthalm. 1991;111:92-99.

3. Gonzales CA, Srinivasan M, Whitcher JP, Smolin G. Incidence of corneal ulceration in Madurai District, South India Ophthalmic Epidemiol. 1996;3:159-66.

4. Hagan M, Wright E, Newman M, Dolin P, Johnson G. Causes of Suppurative keratitis in Ghana. Br J Ophthalmol. 1995;79:1024-8.

5. Whitcher JP, Srinivasan M, Upadhyay MP. Corneal blindness: a global perspective Bull World Health Organ. 2001;79:214-21.

6. Erie JC, Nevitt MP, Hodge DO, Ballard DJ (1993). Incidence of ulcerative keratitis in a defined population from 1950 through 1988. Arch Ophthal. 1993;111:166571.

7. Upadhyaya MP, Karmacharya PC, Koirala S, Shah DN, Shakya S, Shrestha JK. The Bhaktapur eye study: ocular trauma and antibiotic prophylaxis for prevention of corneal Ulceration in Nepal. Br J Ophthalm. 2001;85:388-92.

8. Leck AK, Th omas PA, Hagan M. Aetiology of suppurative corneal ulcers in Ghana and south India, and epidemiology of fungal keratitis. Br J Ophthalmol. 2002;86:1211-15.

9. Srinivasan M, Christine A, Gonzales et al. Epidemiology and aetiological diagnosis or corneal ulceration in Madurai, south India. Br J Ophthalm. 1997;81:965-971 
10. Norina TJ, Rainan S. Microbial keratitis aetiological diagnosis and clinical features in patients admitted to Hospital University Sains Malaysia. Singapore Med J. 2008;49(1):67.

11. Chirambo MC, Tielsch JM, Katz J. Blindness and visual impairment in Southern Malawi. Bull WHO. 1986;64:567-72.

12. Brilliant LB, Pokhrel RP, Grasset NC, Lepkowski JM, Kolstad A, Hawks W et al. Epidemiology of blindness in Nepal. Bull WHO. 1985;63:375-86.

13. Basak SK, Basak S, Mohanta A. Epidemiological and microbiological diagnosis of suppurative keratitis in Gangetic West Bengal, Eastern India. Indian J Ophthalm. 2005;53:17-22

14. Hagan M, Wright E, Newman M, Dolin P Et al. Causes of suppurative keratitis in Ghana. Br J Ophthal. 1995;79:1024-28.

15. Dhakhwa. Causative organisms in microbial keratitis. Nepal J Ophthalmol. 2012;4(7):119-127

16. Upadhyaya MP, Karmacharya PC, Koirala S, Tuladhar NR, Bryan LE, Smolin G et al (1991). Epidemiologic characteristics, predisposing factors, and aetiologic diagnosis of corneal ulceration in Nepal. Am J Ophthalm. 1991;111:92-99.

17. Lavaju P, Khanal B, Amatya R, Patel S. Demographic pattern, clinical features and treatment outcome of patients with infective keratitis in the eastern region of Nepal. Nepjoph. 2009;1(2):101-106.

18. Williams G, Billson F, Husain R, Howlader SA. Microbiological diagnosis of suppurative keratitis in Bangladesh. Br J Ophthalm. 1987;71:315-21.
19. Amatya R, Shrestha S, Khanal B et al. Etiological agents of corneal ulcer: five years prospective study in eastern Nepal. Nepal Med Coll Journal. 2012;14(3):219-222

20. Upadhyaya MP, Karmacharya PC, Koirala S, Shah DN, Shakya S, Shrestha JK et al. The Bhaktapur eye study: ocular trauma and antibiotic prophylaxis for prevention of corneal ulceration in Nepal. Br J Ophthalm. 2001;85:38892.

21. Poole TR, Hunter DL, Maliwa EM, Ramsay AR, Aetiology of microbial keratitis in northern Tanzania [letter]. Br J Ophthalmol. 2002;86:941-2.

22. Thomas PA, Kaliamurthy J. Mycotic keratitis: epidemiology, diagnosis and management. Clin Microbiol Infect. 2013;19(3):210-20. doi: 10.1111/14690691.12126. Epub 2013 Feb 9.

How to cite this article: Qayum S, Gupta V, Chauhan J. Retrospective analysis of microbiological profile of patients with infective keratitis: North Indian perspective. Indian J Clin Exp Ophthalmol. 2018;4(4):454-457. 